\title{
BIM AUTOMATION: ADVANCED MODELING GENERATIVE PROCESS FOR COMPLEX STRUCTURES
}

\author{
F. Banfi ${ }^{\text {ab }} *$, S.Fai ${ }^{\text {a }}$, R. Brumana ${ }^{a}$ \\ ${ }^{\text {a }}$ Carleton Immersive Media Studio (CIMS), Carleton Universisty, Ottawa, Canada \\ sfai@.cims.carleton.ca

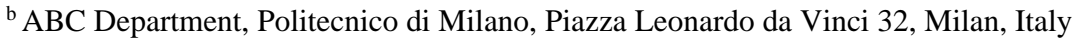 \\ (fabrizio.banfi, raffaella.brumana)@polimi.it \\ http://www.gicarus.polimi.it
}

Commission VI, WG VI/4

KEYWORDS: BIM, Automation, Modelling, NURBS, LOD, Structural Analysis, FEA, Simulation

\begin{abstract}
:
The new paradigm of the complexity of modern and historic structures, which are characterised by complex forms, morphological and typological variables, is one of the greatest challenges for building information modelling (BIM). Generation of complex parametric models needs new scientific knowledge concerning new digital technologies. These elements are helpful to store a vast quantity of information during the life cycle of buildings (LCB). The latest developments of parametric applications do not provide advanced tools, resulting in time-consuming work for the generation of models. This paper presents a method capable of processing and creating complex parametric Building Information Models (BIM) with Non-Uniform to NURBS) with multiple levels of details (Mixed and ReverseLoD) based on accurate 3D photogrammetric and laser scanning surveys. Complex 3D elements are converted into parametric BIM software and finite element applications (BIM to FEA) using specific exchange formats and new modelling tools. The proposed approach has been applied to different case studies: the BIM of modern structure for the courtyard of West Block on Parliament Hill in Ottawa (Ontario) and the BIM of Masegra Castel in Sondrio (Italy), encouraging the dissemination and interaction of scientific results without losing information during the generative process.
\end{abstract}
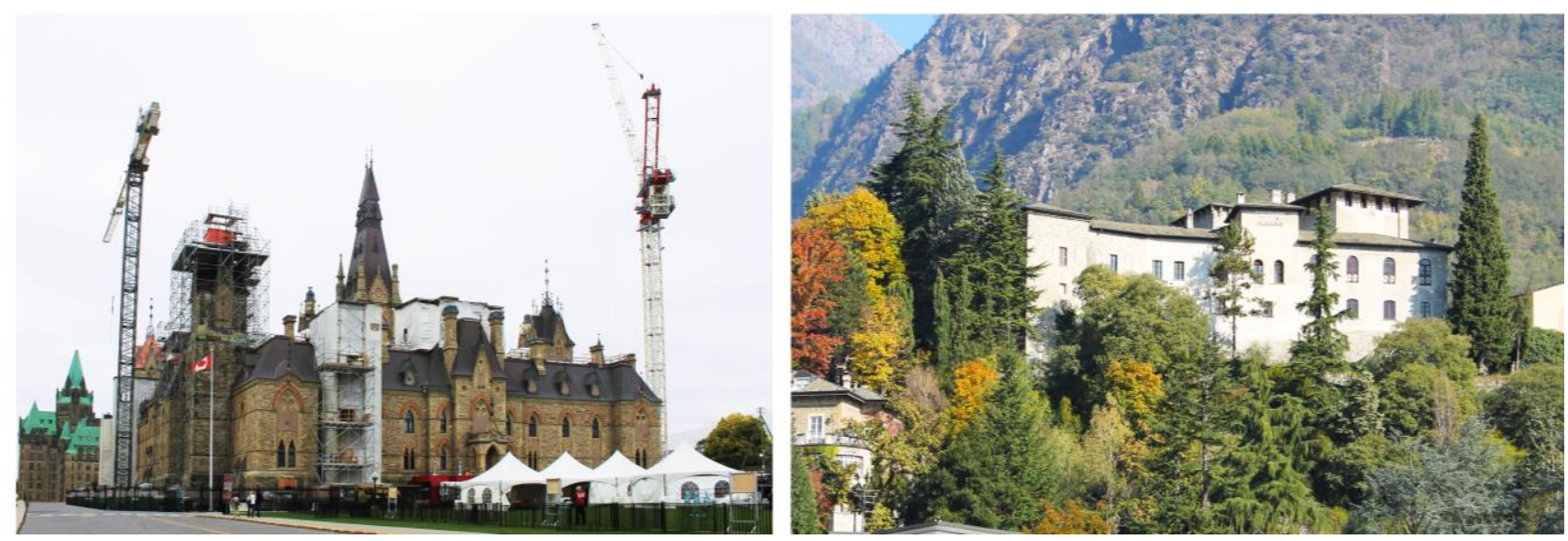

Fig. 1. West Block on Parliament Hill in Ottawa, (Ontario XIX century ) and Masegra Castel in Sondrio (Italy, XIV century)

\section{INTRODUCTION}

\subsection{General context}

The generation of as-built BIM model, in support of the building's life cycle, is assisted by the continuous development of specific modelling and 3D data capture tools. Advanced modelling techniques determine the quality and the flexibility of BIM, (Banfi F., 2016) improving the dissemination of information related to three-dimensional elements during the analysis process (Brumana R., 2014. Della Torre S., 2015)

$3 \mathrm{D}$ data capturing tools and software, however, are rapid and accurate solutions to surveying buildings. Laser scanning technology collects 3D space information into a computer file called point cloud (Volk R., 2014). Modeling requires long generative time causing an increase in costs related to the

\footnotetext{
* Corresponding author
} 
construction of the model based and a slowdown of management processes for building rehabilitation.

The improvement of coordination and production in the Architecture, Engineering and Construction industry (AEC) needs new approaches and methodologies to increase the flexibility of modeling for existing structures, maintaining the complexity of the 3D survey data (cloud-to-3D model)

(Barazzetti L. 2015; Fai S., 2011). The aim of this work is to introduce innovative features that can improve the generative model process through the support of new technologies and new digital tools, demonstrating how the application of this method can reduce the time of construction of complex models.

This generative approach is a resource that can better describe the building, both regarding management process (Della Torre S. 2015) and structural behaviour (Barazzetti L. 2015) for finite elements analysis (BIM to FEA). Advanced Modeling Technique (AMT) has led to combine existing data (point clouds) with structural databases of 3D objects, ensuring adequate three-dimensional representations (Oreni D. 2014) of each element (beams, columns, construction anchors, connections, joist, formwork, frames, and trusses) and reducing critical generative issues for BIM of complex structures.

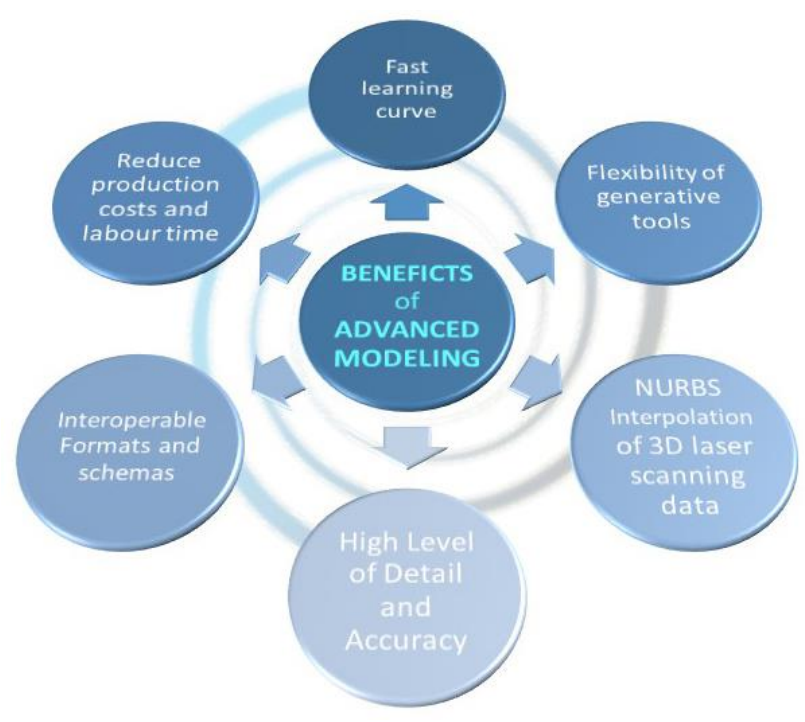

Fig. 2. Benefits of Advanced Modeling for complex BIM generation.

These advantages can be obtained if the model and its database are successfully realised (Murphy M., 2013). This approach considers the morphological and typological aspects (Mezzino D., 2016), technological transformation for different types of analysis (format and software), interoperable requirements for analysis applications (FEM, MA) and new standards that determine the quality of the model.

\subsection{Level of Detail (LoD) and ReverseLoD for advanced modelling techniques}

Levels of details (LoDs) allow one to define the complexity and quality of the model. LoDs simplify the reading of geometric model and ensure the veracity of associated information during the building process. For this reason, nations that are most advanced on reforms have been undertaken, in the last few years, programs to increase transparency through several initiatives becoming standards and national regulations for the construction sector (NBS, 2016). The transmission clearly implies a duty to report all the characteristics of the model, both in morphological and typological aspects. On the other hand, from an operational and generative point of view, this new standard dose not simplify proper generation but pose many generative constraints for modeling existing buildings. The qualitative value of the 1 should not be defined a priori but gradually reached during its life cycle. The primary objective to achieve an appropriate 'as built' model should be determined according to the project purposes (Fai S., 2014).

Unfortunately, BIM platform works against a user-friendly modeling, imposing their languages with the introduction of additional constraints during the generation process. One only has to look at the rigidity of the basic elements that form the three-dimensional parametric database software. A large number of research projects have focused on this issue in past years, but just a restricted circle of them has examined problems linked at personalization of these elements (Fai S., 2013; Barazzetti L. 2015; Murphy M., 2013). With this recent technical progress in mind, significant development of tools and more advanced modeling algorithms bring substantial benefits to the design and construction of new buildings.

On the other hand, the generation of three-dimensional models of existing buildings requires the use of unique threedimensional elements with their peculiarity and not grouped in simplified architectural databases (library and family). The morphological and typological characteristics of an existing building are part of its heritage and modeling should ensure transmission of proper information (authenticity of materials) and a real representation (uniqueness of geometric aspect). This means that it is not possible to obtain complete information from 3D data capture of the structure. It is therefore convenient to provide the application of the ReverseLoD method (Banfi, 2016), distinguishing between elements created based on point clouds and elements do not have real geometry value. The work investigates the world of AMT and the utility of BIMs through different interoperable formats.

The objectives of this research are:

- Establish and maintain a generative approach that promotes as-built model through the use of different modelling procedures;

- The integrated use of pure modelling (NURBS elements) into parametric BIM application;

- Demonstrate how the use of this method can reduce time and cost, improving automation process;

- Show how BIM can support different levels of detail while maintaining the complexity of 3D data captured for finite element analysis (FEA).

The process is based on previous research work carried out in recent months in the field of BIM through two significant case studies. The first case study is the BIM of the modern structure, i.e. the courtyard of Western Departmental Building on Parliament Hill in Ottawa (Ontario).

The second case study is a historic wooden beam system of Masegra Castel in Sondrio (Italy). The obtained results showed that AMT are essential to handle complex reconstructions not only for technical purposes but also for improvement in interoperability procedures for integration of BIM and MA/FEA. 


\section{BIM GENERATION}

\subsection{Processing of 3D Data Capture}

Thanks to the integrated use of laser scanning, photogrammetry and total station it has been possible to achieve a proper base for the 3D reconstruction. The level of detail (LOD) of the 3D models and the level of accuracy (LOA) between point clouds and BIM depends on the quality of the 3D survey data (point clouds and geodetic network). It is possible to establish the georeferenced position of each point in the real space using advanced 3D surveying techniques. Each point has specific coordinates $(\mathrm{x}, \mathrm{y}, \mathrm{z})$ in the space and can be utilised in the digital environmental in order to get as-built BIM.

The first method of point clouds collection is Light Detection And Ranging (LIDAR), which is usually called laser scanning. Laser scanners emit laser pulses resulting in 3D objects location. The use of lasers determine the locations of a vast number of $3 \mathrm{D}$ points and their spatial information is indexed into a computer file. The main benefit of this technique is the acquisition of the morphological characteristics of the object detected in a short time, giving an accurate base for the BIM generation. Unfortunately, the size of point clouds formats is one of the main issues for the modeling process causing a slow data processing. The average scan resolution of the two following case studies is about 50 million points per scan. The instrument used is a Faro® Laser Scanner Focus 3D.

The second method of point clouds collection is photogrammetry an efficient and less costly solution that determine 3D coordinates using images. The algorithms that allow measurements to be taken faster are included in applications that manage large point clouds. The most modern photogrammetry stand-alone applications used to extract geometric information from two-dimensional images and videos are Agisoft ${ }^{\circledR}$ PhotoScan, and RhinoPhoto ${ }$, PhotoModeler, ContextCapture, 3D Zephyr, Pix4D, etc. Theses software can create point clouds that have an excellent level of accuracy when compared to those generated by laser scanners.
Photogrammetry also requires adequate natural and artificial illumination conditions. Laser scanning does not need an exterior light source. Processing of these types of 3D data capture is facilitated by the implementation of new 3D scanning applications that convert point cloud formats into new formats for BIM generation software (Fig. 3). For instance, laser scans and images are registered automatically by Autodesk ${ }^{\circledR}$ ReCap 360 Pro.

The main procedures applied during the processing are:

- Import and manage scans in various formats, Autodesk ${ }^{\circledR}$ Recap support all text-based and 3D laser scan data such as e57, .rds, .txt, .xyz, .zfs, .rcp, .ptg, .pts, .pcg, .ptx, etc.

- Integration of photos and laser scans to create point clouds to edit, clean and measure tagging objects.

- Thanks to Bentley Pointools or other similar application is possible to define the number of the point for each scan. The quantity of the points determines the quality of the models.

- Error verifications of measurement for field and document management.

- Connect building project teams using Cloud Services of Autodesk ${ }^{\circledR}$ BIM 360 Team reducing the time needed to link multi-users.

The last paragraphs show what the proper requirements for an accurate $3 \mathrm{D}$ reconstruction, using scans with a deviation value of $2 / 3 \mathrm{~mm}$ between points and 3D object.

\subsection{Advanced modelling and NURBS technology}

Implementing a 3D model requires (i) analysis of 3D data captured in digital environments and (ii) specific use of generative tools. 3D modeling is the generative process of developing three-dimensional elements (surfaces, poly surfaces, and solids) starting with generative elements such as lines, segments, spline curves and polygons. These entities are called 'geometric primitives' in CAD systems. They provide the basis for complex 3D elements in primary pure modeling applications such as McNeel® Rhinoceros, Autodesk®Maya, Autodesk® Autocad, and the open source 3D Blender®.
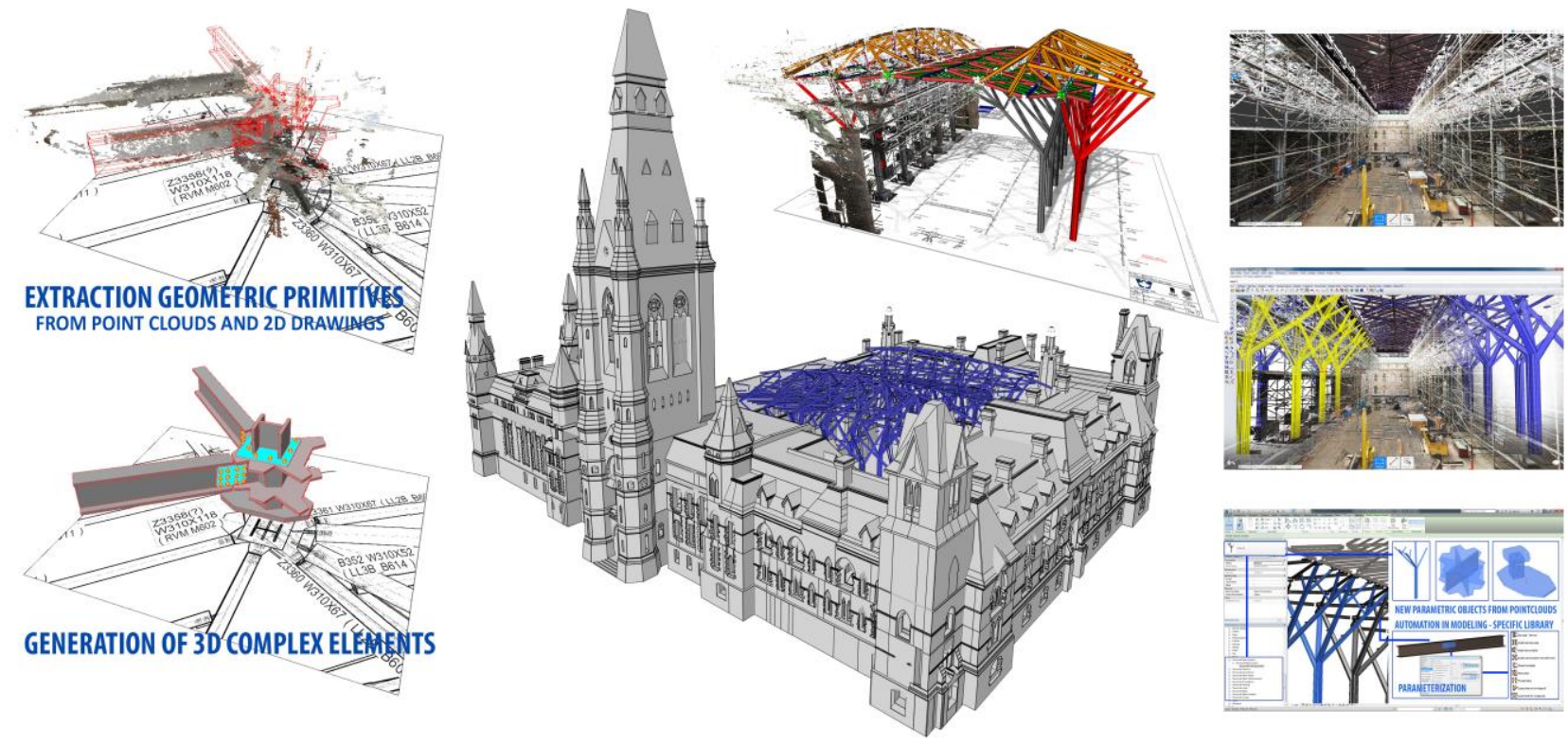

Fig. 3. The generation process of Modern Structure of West Block. Geometric primitives and 3D solids can be extracted from scans. The deviation value between point clouds and $3 \mathrm{D}$ objects is $2 \mathrm{~mm}$. 
These applications support pure modeling, animation, simulation, rendering, video editing expressed by mathematical algorithm and functions such as Non-uniform Rational Basis splines (NURBS) used in computer graphics for generating and representing complex 3D elements (Piegl L. A., 1997).

Their first peculiarity is the interpolation of 3D points and curve line segments reducing great number of application block, carrying out complex shapes with a high level of accuracy and millimetre-level precision. The second advantage is related to the flexibility to generate a large variety of shapes from point clouds by using advanced modeling tools: operation like translations, rotations can be applied to their control points NURBS reduce the memory consumption, achieving a real geometric interpretation of 3D data captured by laser scanning.

\subsection{From NURBS to BIM. Clustering of export and import schemas for interoperable modeling practices}

Lack of advanced modeling tools based on NURBS interpolation in the parametric BIM platform has requested to identify and optimise interoperable practices and the use of new digital formats (input and output).

Integration of pure modeling and NURBS technology in parametric software such as Autodesk ${ }^{\circledR}$ Revit and ArchiCAD Graphisoft ${ }^{\circledR}$ has been possible through the development and implementation of output formats. Main formats used to transfer NURBS model into BIM Platform are .dwg and .sat.

For the BIM of Masegra Castel, the NURBS model was converted into .dwg format while BIM of Modern Structure of West Block is used .sat format (ACIS files). The choice of the approach of the export schemas (output) has received specific attention. They require a list of constraints, restrictions and options, which should not be overlooked for a proper recognition of the NURBS model. The ACIS converter supports importation and export of attributes of geometric entities that form solids (3D elements).

Rising modeling labour costs and the need for productivity are driving businesses to automate. Finding a new solution for modeller will be the next challenge.
Importation of file ACIS file in Autodesk ${ }^{\circledR}$ Revit allows semiautomatic recognition. Thanks to the use of automatic tools selection of these geometric entities, it has been possible to reach a high level of semi-automation. Clustering of these schemes helped to define protocols, guidelines useful for asbuilt BIM generation from NURBS models. The recognition of geometric primitives obtained from these schemas increases automation in modelling. After importing the NURBS model (with proper schemas), it was possible to have an automatic recognition of the geometric primitives and to obtain the parametrization of the 3D elements (surfaces and solids) into Revit's database. This application has various advanced modelling tools, but the generative logic does not allow the NURBS and high level of modelling flexibility.

The proposed procedure helps to avoid the modelling in parametric software and directly recognise 3D elements created in McNeel ${ }^{\circledR}$ Rhinoceros or Autodesk®Maya.

Specific components ensure the automation process in the BIM platform that identifies geometric primitives since the beginning of the generative process. This mathematical alignment, in addition to the reduced lead-times, allows one to insert and create complex elements for the library of the BIM Platform (Revit's database).

The most important peculiarity of the $3 \mathrm{D}$ parametric object is the possibility to link a wide range of information such as wall, wood and steel stratigraphic and physical and technical characteristics of the materials of the structures. Also, as highlighted in the following picture (Fig. 6), the wooden roof structure of Masegra Castel is composed of beams of various dimensions, while the modern structure of the West Bloc is made up of pillars, steel beams and connections designed for this specific rehabilitation project.

This structural connection add-in is an API-solution. The user interface (designed to improve the database of detailed structural connector geometry) has allowed further changes of additional parameters in the Revit modeling environment. One of the most complex and time-consuming phases of the design of the structure are the connections.
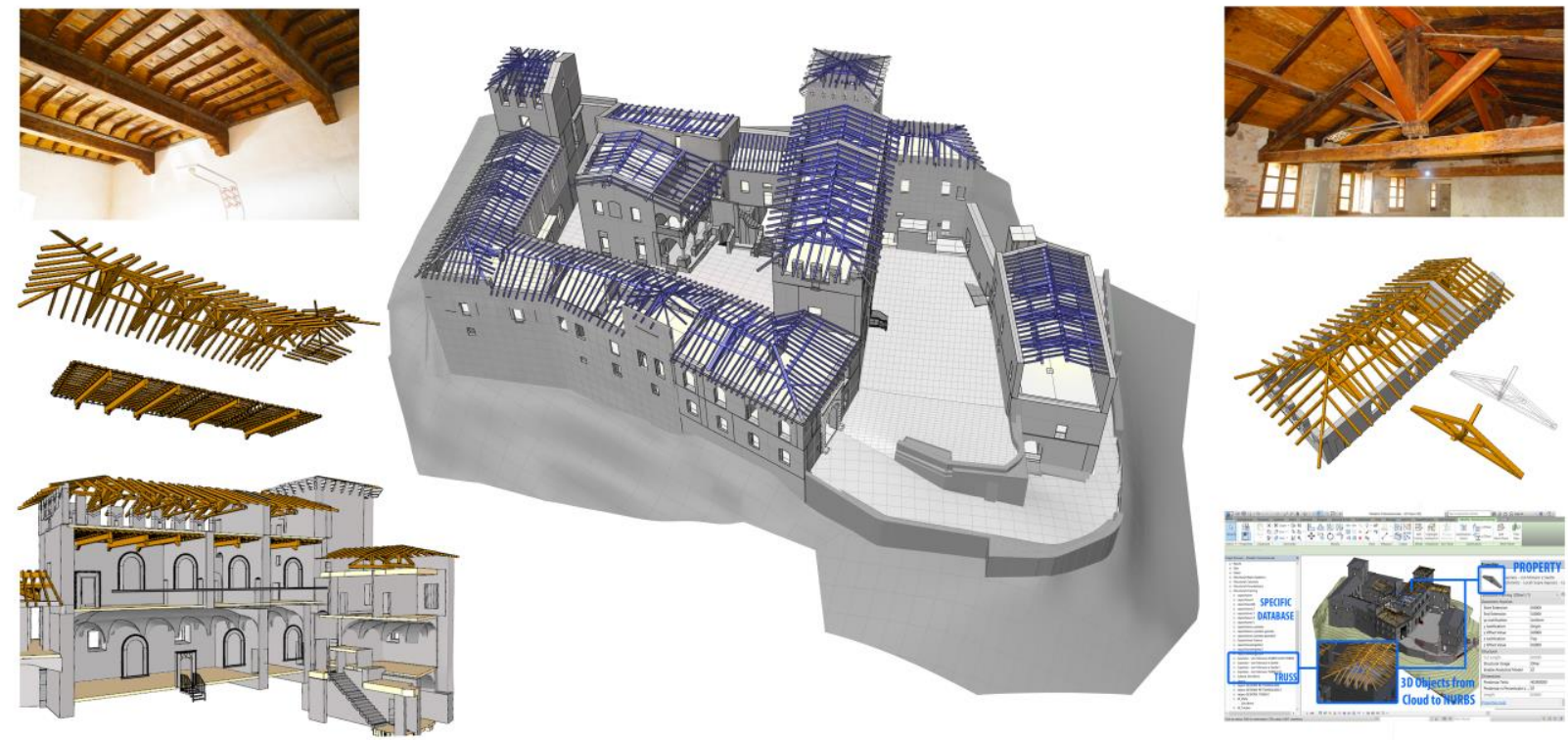

Fig. 4. From NURBS models to BIMS Library. 3D structural elements, wooden beams, truss and joints are enclosed in new database of Masegra Castel in Sondrio. 
This complex modeling process requires precision and efficiency: Advance Design Steel Connections (ADSC) has allowed one to create an accurate module that offers multiple advantages when it comes to connection design and verification.

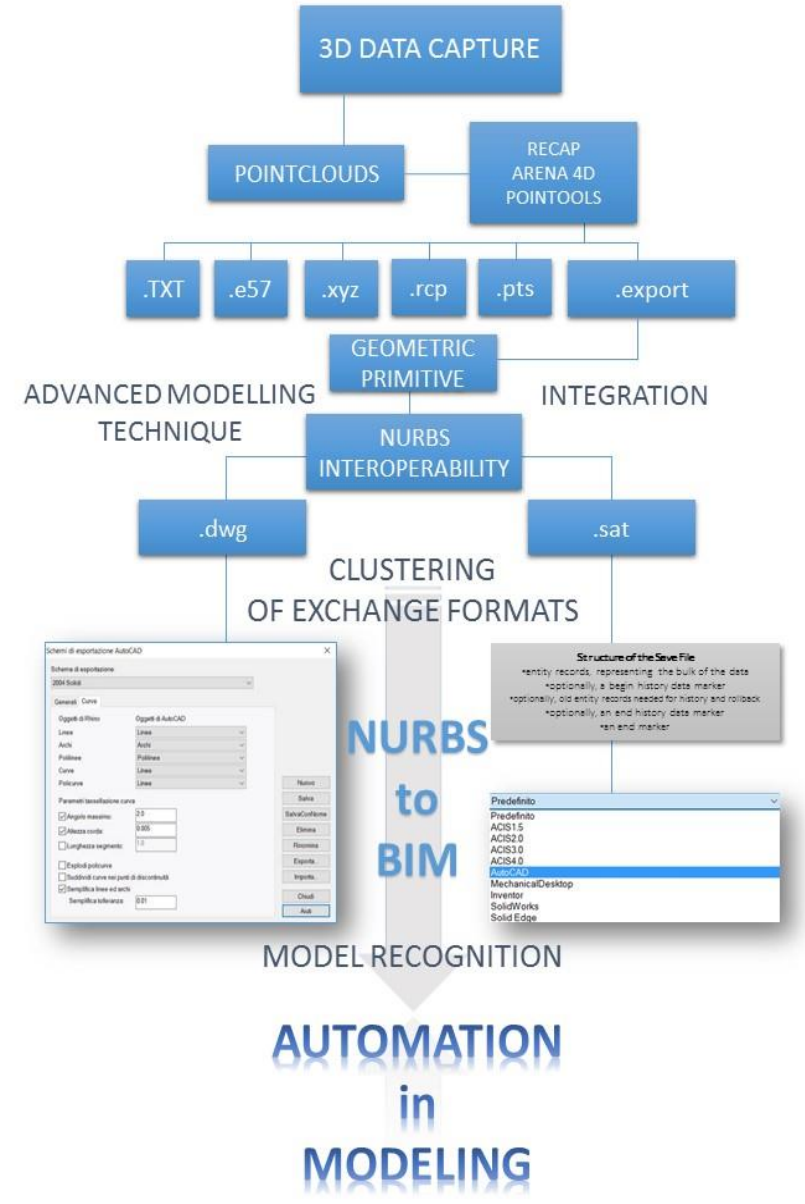

Fig. 5. Automation in modelling. Clustering of exchange formats and their schemas (.dwg. and .sat ).

\subsection{From BIM to MA and FEA. Automation in modeling}

An overriding issue is the lack of flexibility the interoperable process. The proposed generation approach permits transferring a complex BIM into a finite element analysis. BIM Platform stresses the lack of NURBS interpolation tools (Cloud to complex NURBS elements) and the consequent technical transmission of the data (material, stratigraphic information, physical and technological properties and historical phases).

The morphological and typological aspects of structural elements have been transferred and mutually recognised by finite element analysis application such as Midas ${ }^{\circledR}$ FEA, Autodesk ${ }^{\circledR}$ Advance Steel, new Revit's tool called Connection, Autodesk ${ }^{\circledR}$ Inventor Pro, Autodesk ${ }^{\circledR}$ Simulation and the plugin for Rhino called Scan to Solve (Fig.6).

Testing BIM of the new structure of the West Block is characterised by the generation of parametric steel detailing, steel fabrication, and steel construction with an extensive library of parametric steel connections. These connections are included in software's database. Their main peculiarity is to change any structural elements' size automatically adjusting the different types of connection.

This final procedure allowed advanced nonlinear analysis is defining the paradigms of complexity and automation process for civil and structural engineering buildings. This application is specialised for refined method analysis, which is required by design codes for complex 3D elements. Transfer of wooden/steel roof BIMs with complex geometry has posed a variety of challenges for knowledge of advanced modelling techniques and geometric entities. The model has been converted to a specific interoperable format to perform local analysis for 3D objects. It has been fundamentally formed by the interlocking relationship of various geometric objects.

Auto-meshing algorithms for generating optimal surface meshes based on the 3D NURBS elements provided a significant improvement of the level of accuracy of the calculations and structural results (NURBS Interpolation BIM to MA/FEA).

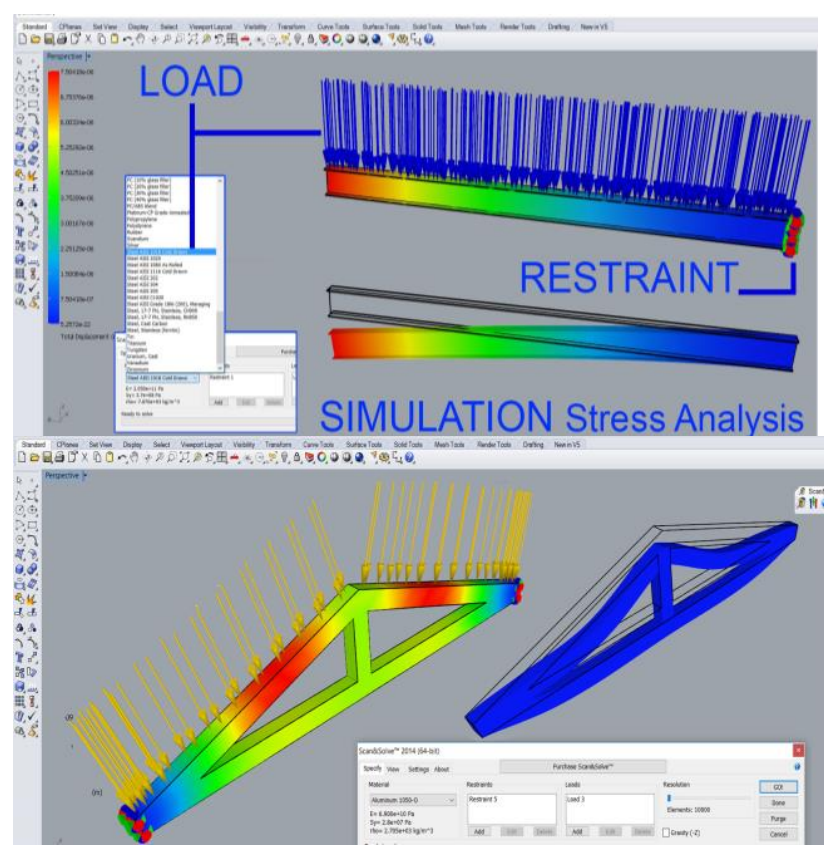

Fig. 6 NURBS Interpolation for BIM to MA/FEA. Auto-mesh algorithms can include geometric primitives such as points, curves with surfaces for mesh generation.

The method permits to achieve and verify a high level of accuracy (LoA) for each architectural and structural elements. The flexibility of NURBS modeling allows the generation of the complex element by the interpolation of the points which form the point clouds and the $3 \mathrm{D}$ wireframe.

These two entities are the unique constraints useful for the generation of complex BIM. The automatic extraction defined by advanced NURBS algorithms increase the flexibility of the modeling and the level of detail (LOD) of the model. It is simple to create and parameterize a steel beam or wooden truss because the parametrization of these elements depends on the regular geometric primitives that built up the 3D object.

Figure 7 shows the advanced modeling generative process for complex structural elements and how it is possible to achieve a deviation value of $1 \mathrm{~mm}$ between point cloud and 3D objects. 
The method allowed the creation of mediaeval vault of Masegra Castel, reaching an Automatic Verification System (AVS ) of the level of accuracy and precision of elements generated from cleaned point clouds $\left(\operatorname{Step~}^{\circ}{ }^{1}\right)$.

The extraction of generative primitives (step $\mathrm{n}^{\circ} 2$ ) and the automatic generation of complex NURBS surface allowed the parametrization in Autodesk Revit (step ${ }^{\circ} 4$ ) of the 3D object (step $\mathrm{n}^{\circ} 3$ ). This step permitted to obtain the thickness of each part of the vault, allowing the association of information (step $\mathrm{n}^{\circ} 6$ ) in the parametric application, the stress analysis and the automatic simulation (step $n^{\circ} 7 / 8$ ).

High level of BIM automation provides an accurate, innovative and fast generation approach to solve the problems of modeling practices: time, cost and flexibility. In fact, modeling cost is a critical point for companies and studios in the AEC sector.

On the other hand, the level of detail (LoD) should be provided for any update to 3D survey data, 2D drawings and design integration during the generative process.

Because of the risk of high cost for analysis and BIM generation, LoD should not be specified at the beginning of the generative process, but defined and limited in time based on the needs and goals of the projects.

It was agreed that the components of the BIM should be developed in such a way that LoD could be easily added or subtracted in the future for cases where the users may opt for more (heritage record) or less (facilities management) information ( Fai S., 2014).

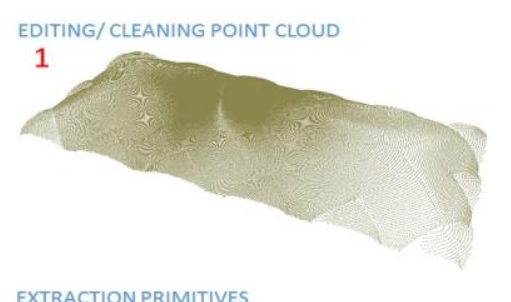

DEFINTION MATERIALS, LOADS AND CONSTRAINTS

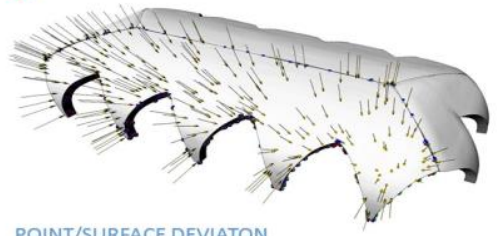

POINT/SURFACE DEVIATON

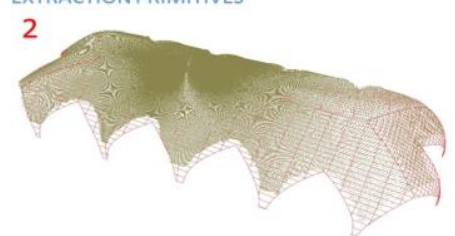

NURBS INTERPOLATION

5
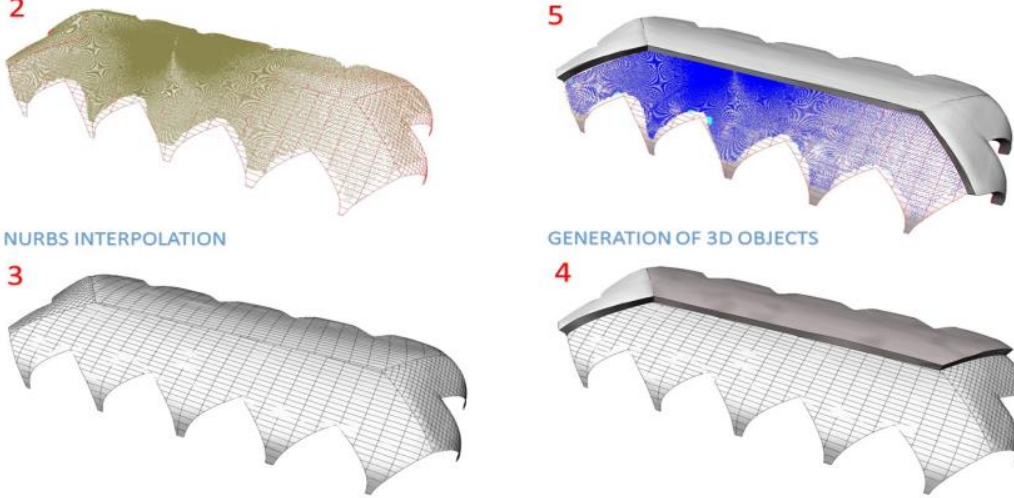

GENERATION OF 3D OBJECTS
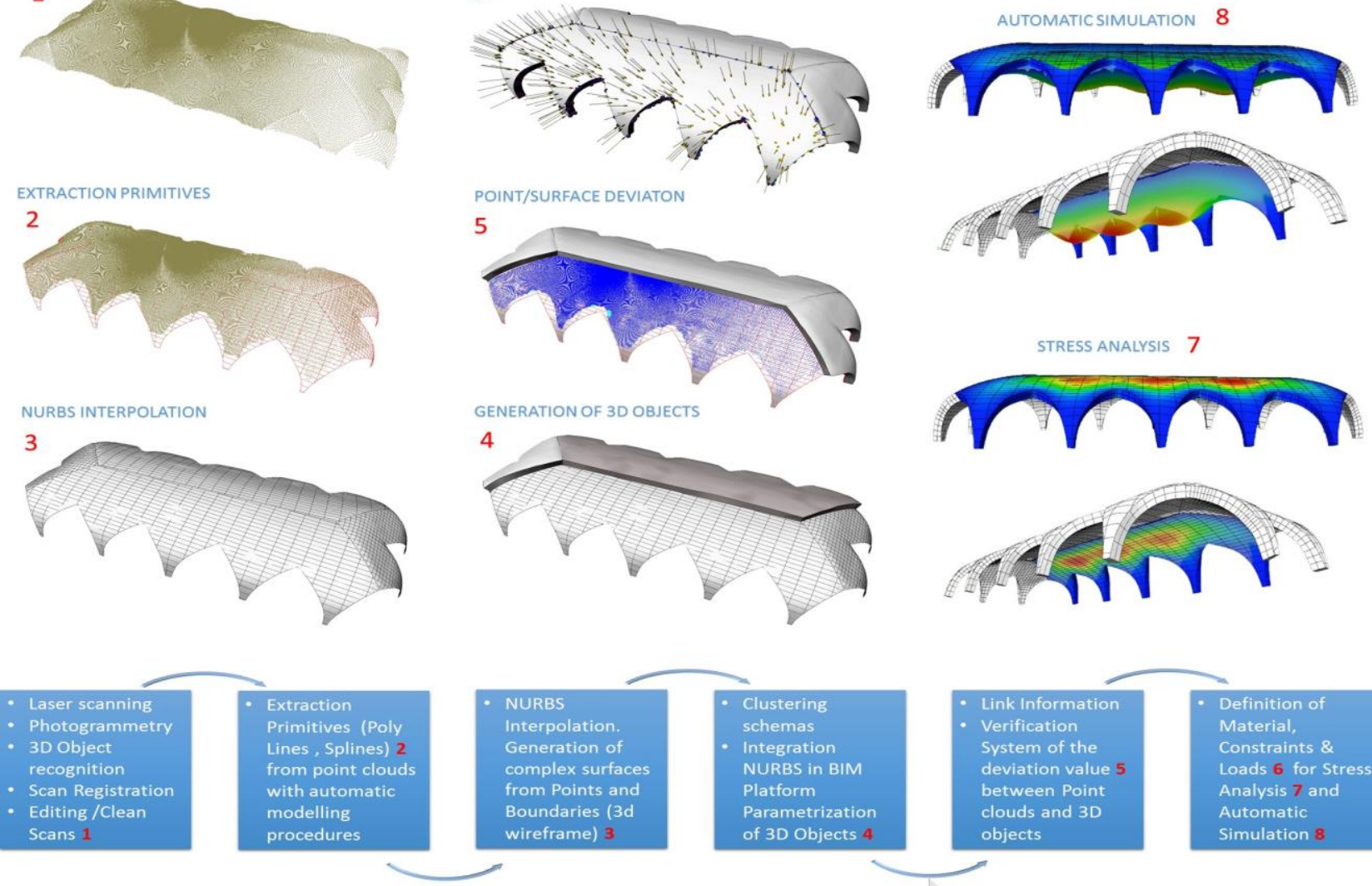

ADVANCED MODELING GENERATIVE PROCESS FOR AS-BUILT BIM

5 DEVIATON VALUE

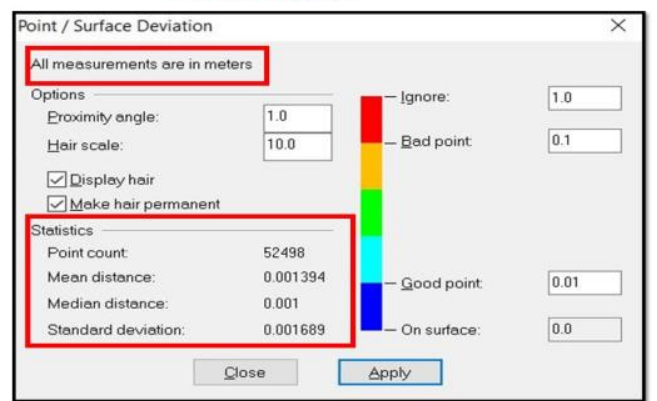

7/8 STRESS ANALYSIS VALUE

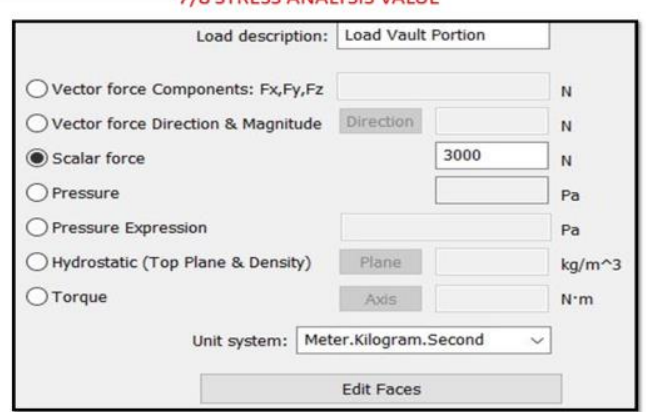

Fig. 7. Advanced Modeling Generative Process for as-built BIM. The method allows the creation of 3D objects of complex structural elements such as the main vault of Masegra Castle. The level of automation (LoA) permits to achieve a deviation value of 0,001689 $\mathrm{m}$ between 52489 points and complex element, enabling architects and engineers to achieve model numerical simulations by Finite Element Analysis (FEA). 


\section{RESULTS}

\subsection{Advantages of the proposed method}

Benefits of modeling techniques applied at the BIM generation process (Cloud to BIM to FEM) are manifold:

- 3D Data Capture techniques (3D Scanning and Photogrammetry) of existing buildings capture the real shapes of architectural and structural elements.

- Production of accurate 2D drawings and consistent at any stage of the design

- Control, update and discovery of errors in 2D drawings made previously without 3D survey

- Automatic corrections as a result of changes (2D-3D)

- Integration and management of the model with information obtained during the life cycle of the building

- Automatic extraction of plan, section and elevation with a deviation value of $1 \mathrm{~mm}$.

- Visualisation and simulation more accurate (Virtual and Augmented reality, VR-AR)

- Improvement of the preliminary analysis through the use of interoperable models (FEA-BEM)

- Improve collaboration between the various disciplines for the analysis of the building through a shared model (shared BIM cloud-server)

- Performance of the construction as-built (Structural Analysis, Calculation and Simulation based on An accurate H-BIM)

- Discovery of errors in the design before construction (Clash detection and Model checking)

3.2 Possible improvement and fields of application of the proposed method

Using the model project as the basis for the design and rehabilitation of the building

- Design synchronisation with the construction planning (BIM to CoSIM)

- Portability of the model (BIM to field)

- Extraction of the cost estimates at the design stage (BIM 5D)

- Building and manufacturing stage

- Using the project model as a basis for the manufacture of the components

- Facility Management and Asset Management

\section{CONCLUSION}

Transmissibility of knowledge and the development of Information Technologies play a critical role in BIM innovation. Building Information Modeling is transforming the management of existing buildings, throughout their entire life cycle.
BIM is not simply the use of 3D applications, but a process that integrates all the information related to a construction project for planning, analysis and design phase (PMLC) to the maintenance and management years after the rehabilitation.

The first goals for the future of the proposed modeling technique, applied to BIM of Masegra Castel, is the integration within the field of architectural conservation through the implementation of a BIM platform to manage complex shapes and a great quantity of historical and material information.

Architectural conservation is divided into four standards such as preservation, rehabilitation, restoration and reconstruction of the historic building. In a future perspective, Building information modeling should be a primary tool in heritage conservation (BIM to HBIM) in order to improve knowledge and dissemination in digital environments.

The second goal will improve the proposed method and its interoperability (formats and tools), facilitating the proposed new paradigm of automation in modeling, as in the BIM of the modern structure of the West Block. All stages of the construction life cycle from initial planning and design, through the construction of the facility, its operation and maintenance, to the eventual dismantling, should be transferred in specific applications for advanced nonlinear analysis for civil, structural engineering and simulation applications (BIM/HBIM to FEA/MA). Clustering of exchange formats and their schemas (.dwg. and .sat ) has allowed the proper transfer of complex entities in various application, avoiding the use of IFC and expensive development of new exchange strategy.

This study underlines the real need to open two scenarios:

1 - Multinational software corporation should be integrate NURBS algorithms in the BIM application in order to improve the management and generation of complex 3D elements from point clouds into principal BIM application (Autodesk Revit, Graphisoft ArchiCAD). This development could me help the BIM generation and reduce time and cost of the modeling.

2 - The Industry Foundation Classes (IFC) data model should improve a new level of exchange definition for its formats. In the future, many BIM applications will have the need to receive open exchange formats able to maintain a high level of accuracy and detail of detected elements, both in morphological and in typological aspect. The utility of BIM will be based on the transferability and interoperability of the related exchange formats. BIM application should be able to achieve various types of analysis and software using one format.

Engineers could use the proposed approach for projects such as plain and reinforced wooden and steel structures, improving the level of accuracy of the calculation and simulation analysis on complex existing systems.

Finally, future research could address and improve the proposed method with particular attention to economic benefits. The costbenefit analysis could promote the dissemination of the BIM technology and encourage companies, institutions or not-forprofit organisations to finance research aimed at automating the creation of complex BIMs in order to increase the level of shared knowledge and improve the management of our built heritage over time. 


\section{ACKNOWLEDGEMENTS}

This work was supported by Carleton Immersive Media Studio (CIMS) is a Carleton University research centre, Ottawa (Ontario) and GIcarus Lab is a research centre in $\mathrm{ABC}$ Department (Architecture, Built Environment and Construction Engineering) in Politecnico di Milano (Italy).

The authors want to thank ICT, Survey and Monitoring staff of both labs.

The work has also been supported by Interreg project "La Conservazione Programmata nello Spazio Comune Retico'(CPRE) and New Paradigms/New Tools for Heritage Conservation in Canada.

This project was funded in part by the Social Sciences and Humanities Research Council (SSHRC) of Canada.

\section{REFERENCES}

Autodesk ${ }^{\circledR}$ 2017, Steel Connections for Revit https://knowledge.autodesk.com

Autodesk ${ }^{\circledR}$ Research, 2017, The Future of Making Things: AI in Design and Manufacturing

https://www.autodeskresearch.com/news/future-making-thingsai-design-and-manufacturing

Banfi F., 2016. Building Information Modelling - A Novel Parametric Modeling Approach Based on 3D Surveys of Historic Architecture. 6th International Conference, EuroMed 2016, Nicosia, Cyprus, October 31 - November 5, 2016, Proceedings, Part II. Digital Heritage. Progress in Cultural Heritage: Documentation, Preservation, and Protection, ISBN 978-3-319-48495-2, pp. 116-127

Barazzetti L., Banfi F., Brumana R., Previtali M., 2015. Creation of Parametric BIM Objects from Point Clouds Using Nurbs. The Photogrammetric Records, 30, 152. pp. 339-362

Barazzetti L., Banfi F., Brumana R., Gusmeroli G., Previtali M., Schiantarelli G., 2015. Cloud-to-BIM-to-FEM: Structural simulation with accurate historic BIM from laser scans. Simulation Modelling Practice and Theory, V.57, pp. 71-87.

Brumana, R., Oreni, D., Cuca, B., Binda, L., Condoleo, P., Triggiani, M., 2014. Strategy for integrated surveyingtechniques finalized to interpretive models in a byzantine church, Mesopotam, Albania. International Journal of Architectural Heritage, pp. 886-924
Fai S., Graham K., Duckworth T., Wood A., 2011. Building Information Modelling and Heritage Documentation. in XXIII CIPA International Symposium, Prague, Czech Republic

Fai, S., Rafeiro, J., 2014. Establishing an appropriate level of detail (LoD) for a building information model (BIM) - West Block, Parliament Hill, Ottawa, Canada. ISPRS

Annals of the Photogrammetry, Remote Sensing and Spatial Information Sciences, 2(5), pp.123-130

Fai, S. \& Sydor, M., 2013. Building Information Modeling and the Documentation of Architectural Heritage: Between the 'Typical' and the 'Specific. Digital Heritage International Congress (DigitalHeritage) Marseilles, France. 731-734.

Della Torre S., 2015. Shaping Tools for Built Heritage Conservation: from Architectural Design to Program and Management. Learning from 'Distretti culturali'. Community Involvement in Heritage. Garant. pp. 93-102

Mezzino D., Wey P., Santana M.Q., 2016. Interpretation of sensor-based $3 D$ documentation. How to manage data and knowledge related to interpretative digital $3 D$ reconstructions of Cultural Heritage? Sander Münster. Published by Springer, Berlin

Murphy, M., McGovern, E., Pavia, S., 2013. Historic Building Information Modelling - Adding intelligence to laser and image based surveys of European classical architecture. ISPRS Journal of Photogrammetry and Remote Sensing, 76, pp. 89102.

NBS. 2016. National BIM Report. https://www.thenbs.com

Oremi D., Brumana, R., Banfi, F., Bertola, L., Barazzetti, L., Cuca, B., Previtali, M., Roncoroni, F., 2014. Beyond Crude 3D Models: From Point Clouds to Historical Building Information Modeling via NURBS. In Digital Heritage. Progress in Cultural Heritage: Documentation, Preservation, and Protection. 8740:175.

\section{Piegl, L. A., Tiller, W., 1997. The NURBS book. Springer}

Percy K., Ward S., Santana M.Q., Morrison M., 2015. T. Integrated Digital Technologies for the Architectural Rehabilitation \& Conservation of Beinn Bhreagh Hall \& Surrounding Site, Nova Scotia, Canada. ISPRS Annals of the Photogrammetry, Remote Sensing and Spatial Information Sciences.

Volk R., Stengel J., Schultmann F., 2014. Building Information Modeling (BIM) for existing buildings - Literature review and future needs. Automaiton in Construciton, pp. 109-127 